ISSN 2073-4344

www.mdpi.com/journal/catalysts

Review

\title{
The Art of Manufacturing Gold Catalysts
}

\section{Laura Prati * and Alberto Villa}

Dipartimento di Chimica Inorganica Metallorganica e Analitica L.Malatesta, Università degli Studi di Milano, via Venezian 21, Milano 20133, Italy; E-Mail: Alberto.Villa@unimi.it

* Author to whom correspondence should be addressed; E-Mail: Laura.Prati@unimi.it; Tel.: +39-02503-14357; Fax: +39-02503-14405.

Received: 17 October 2011; in revised form: 21 November 2011 / Accepted: 7 December 2011 / Published: 21 December 2011

\begin{abstract}
Gold has been considered as an active catalyst only when suitable techniques of preparation provided high metal dispersion. A comprehensive survey of the different methods now available for preparing active gold catalysts is reported with particular attention to the role of the supporting material in determining catalyst characteristics.
\end{abstract}

Keywords: gold; catalysts preparation; heterogeneous catalysts; gold nanoparticles

\section{Introduction}

Gold catalysts have now reached an established important role in the field of catalysis since Haruta [1] and Hutchings [2] disclosed the peculiarity of the activity of this metal in CO oxidation and ethylene hydrochlorination 20 years ago. The use of gold catalysts has been enormously expanded [3,4] but, since the beginning of its story, the use of gold for manufacturing new catalytic systems was affected by the high variation of the catalytic results depending on the preparation method employed related to the support used [5]. In fact many studies stated the importance of the combination of these parameters in determining the morphology of the gold particles and metal-support interaction, both able to profoundly modify the activity and/or the selectivity of the whole catalyst. Therefore a lot of attention has been paid to the preparation of gold catalysts in order to assess as much as possible the relation between support/preparation method and characteristics of the produced materials.

The aim of this paper is to give the reader a survey of the most recent techniques related to any single support in order to provide a rapid guide in the choice of suitable preparation method depending on the desired application. 
For a more complete overview in gold chemistry and applications we suggest the reader refers to the abundant, recent literature resources available [1,2,6-10].

All the general methods for preparing metal supported catalysts have been tested also in the case of gold. However, gold presents peculiar characteristics, namely a low melting point and low affinity for oxides, which contrast the production of gold particles with a catalytic relevant activity, i.e., with nanometric (1-9 $\mathrm{nm}$ ) diameter. In this paper, attention will be paid both to the most commonly used preparation methods, i.e., impregnation, deposition-precipitation, coprecipitation and to special techniques such as vapor-phase deposition, sol immobilization and grinding.

\section{Results and Discussion}

\subsection{Impregnation}

In this method the support is contacted with a solution of the metal precursor, and then it is aged, dried and calcined. Depending on the volume of solution with respect to that of the support, two types of impregnation can be distinguished: the so-called "incipient wetness" impregnation if the solution volume does not exceed the pore volume of the support and the "wet" impregnation when an excess of solution is used. The characteristics of the catalyst strictly depend on the post-treatment conditions (rate of heating, time, final temperature, atmosphere) and, obviously, on the type of supporting materials. In fact during the calcination step sintering of the precursor and reaction between the metal precursor and the support might occur. Moreover the use of different conditions can lead to different metal-support interaction, of fundamental importance for the catalytic applications. It should be noted that in the case of gold, the oxide spontaneously decompose to the metal at $T>200{ }^{\circ} \mathrm{C}$. As the effect of temperature is normally detrimental from the metal dispersion point of view, sometimes a reduction step with $\mathrm{H}_{2}$ or, under basic conditions with $\mathrm{HCHO}$ or $\mathrm{HCOOH}$ can be used instead of calcination [11-14].

Conventional impregnation with chloroauric acid $\left(\mathrm{HAuCl}_{4}\right)$ has shown to produce much lesser active gold catalysts than deposition-precipitation (DP) or coprecipitation (CP). However, the simplicity of the methodology and the convenience of using chloroauric acid as the gold source, make impregnation attractive for industrial scale-up purposes, and because of that, much research has been dedicated to improving the preparation method. The effect of the precursor solution aging in the impregnation preparation of $\mathrm{Au} / \gamma-\mathrm{Al}_{2} \mathrm{O}_{3}$ for $\mathrm{CO}$ oxidation was studied [15]. Solutions of $\mathrm{HAuCl}_{4}$ were aged in $\mathrm{pH}$ ranging from 5 to 11 for $15-720 \mathrm{~min}$. UV/vis spectroscopy showed that during aging, hydrolysis of the $\mathrm{AuCl}_{4}{ }^{-}$complex gave rise to several species. It was found that $\mathrm{Au}$ particle size and loading were influenced by the precursor speciation. A significant improvement in the impregnation method has been reported using a two-step procedure [16]. Impregnation of alumina with chloroauric acid was followed by washing off the excess of Au precursor and the solid is treated with a strong base to convert the chloride to an absorbed hydroxide. Drying and calcination at $400{ }^{\circ} \mathrm{C}$ yielded a catalyst with Au particles having an average diameter of $2.4 \mathrm{~nm}$. The activity of the catalyst is comparable to catalysts prepared by deposition precipitation and is stable to hydrothermal sintering. Quite recently [17] it was also disclosed that in addition to the $\mathrm{pH}$ effect, a relevant role is played also by $\mathrm{Cl}^{-}$ concentration in the solution. In fact $\mathrm{HAuCl}_{4}$ dissolved in $2 \mathrm{M} \mathrm{HCl}$, after reduction by $\mathrm{H}_{2}$ at $250{ }^{\circ} \mathrm{C}$, produced on $\mathrm{Al}_{2} \mathrm{O}_{3}$ metallic particles of $1-2 \mathrm{~nm}$ mean diameter. It should be noted that, in contrast to 
gas phase oxidation, the catalytic behavior in liquid phase oxidation appeared to be not affected by the presence of chloride. A detailed study on the ion exchange between $\mathrm{Al}_{2} \mathrm{O}_{3}$ and $\mathrm{HAuCl}_{4}$ has also been reported as a function of $\mathrm{pH}$ which in turn can modify both the species in the solution and the charge on the support surface [18-20]. It should be noted that this ion adsorption strictly depends on the isoelectric point (IEP) of the supporting material. Oxides with IEP around $7\left(\mathrm{TiO}_{2}, \mathrm{CeO}_{2}, \mathrm{ZrO}_{2}, \mathrm{Fe}_{2} \mathrm{O}_{3}\right)$ produced very active species, whereas acidic support $\left(\mathrm{SiO}_{2}\right)$ or basic $(\mathrm{MgO})$ usually appeared less active. In this regard, the amphoteric character of $\mathrm{Al}_{2} \mathrm{O}_{3}$ (IEP 8-9) is more sensitive to $\mathrm{pH}$ variation.

The impregnation method using as-precipitated wet metal hydroxides as supports and Au phosphine complexes as gold source has been studied [21-24]. As-precipitated hydroxide was impregnated with an acetone solution of $\mathrm{Au}\left(\mathrm{PPh}_{3}\right)\left(\mathrm{NO}_{3}\right)$, probably because a high concentration of $\mathrm{OH}$ at the surface is needed for a suitable interaction between the support and the organo-gold complex. This method has also been named as liquid-grafting (LG). Vacuum drying at room temperature and calcination in air followed. Changes in the activities of both $\mathrm{Au} / \mathrm{Fe}$ oxide and $\mathrm{Au} / \mathrm{Ti}$ oxide catalysts have been attributed mainly to changes of the Au particle size distribution occurring during calcination.

The interaction between the charge that the surface assumes in solution and ionic gold species, can be fruitfully used for preparing Au supported catalyst. Any surface is characterized by a $\mathrm{pH}$ called $\mathrm{PZC}$ (point of zero charge) or IEP (isoelectric point) at which the surface is neutral. At pH below the IEP the surface is negatively charged while at $\mathrm{pH}$ over the IEP, the surface is positively charged. The value for some oxides is reported in the literature [25]. Thus cationic complex such as $\mathrm{Au}$ (ethylendiamine) ${ }_{2} \mathrm{Cl}_{3}$ can interact with negatively charged carbon surface in aqueous solution [26] providing $\mathrm{Au}$ well dispersed on the support surface. In contrast, using $\mathrm{HAuCl}_{4}$, largely aggregated $\mathrm{Au}$ metallic particles were obtained principally due to the redox properties of activated carbon [27] (Figure 1). In fact, the higher variety of activated carbon functionalities than those present on oxides can promote other electrostatic interactions.

Figure 1. TEM image of $\mathrm{Au} / \mathrm{AC}$ prepared by impregnation method.

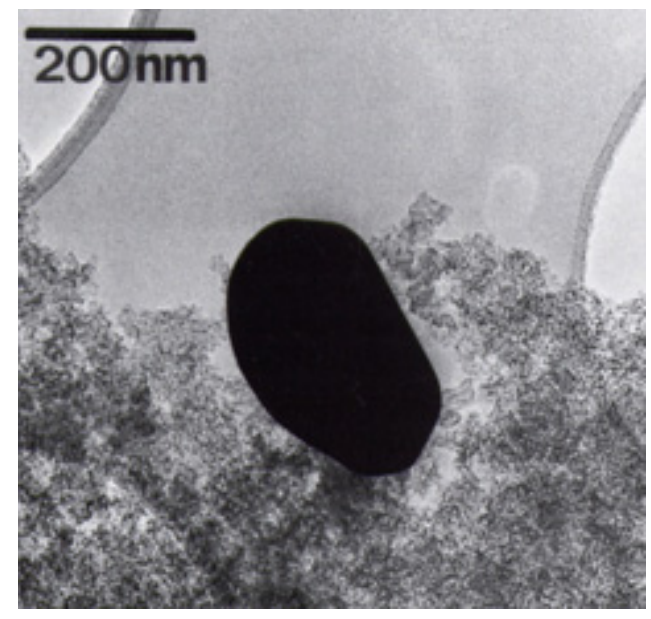

\subsection{Co-Precipitation}

An aqueous solution of $\mathrm{HAuCl}_{4}$ and a water soluble metal salt, generally nitrates, are poured in an alkaline solution. After precipitation the hydroxides or carbonates are filtered, washed, dried and then 
calcined. This technique can be applied to salts of metals in the first row of the transition series in groups 4-12 and also to $\mathrm{Al}$ and $\mathrm{Mg}$, which can be precipitated as hydroxides or hydrated oxides.

$\mathrm{Na}_{2} \mathrm{CO}_{3}$ or $\mathrm{K}_{2} \mathrm{CO}_{3}$ are widely used to adjust the $\mathrm{pH}$ during the coprecipitation process. In contrast to $\mathrm{NaOH}$, carbonates improve the stability of $\mathrm{pH}$. The use of urea as a neutralized was also introduced [28]. Since precipitating gold hydroxide $\mathrm{Au}(\mathrm{OH})_{3}$ is rapidly transformed into soluble $\mathrm{Au}(\mathrm{OH})_{4}{ }^{-}$by increasing the $\mathrm{pH}$, the most efficient range for the precipitation is $7-10$. Bond and Thompson [3,4] suggested ammonium carbonate or bicarbonate as more suitable bases because their ions readily decompose during calcination. Most authors indicate that after co-precipitation the solid is washed until no chloride is detected in the washing solution (i.e., reaction with silver nitrate).

Using this method $\mathrm{Au}$ on $\alpha-\mathrm{Fe}_{2} \mathrm{O}_{3}$ [29-40], $\mathrm{MnOx}$ [41], $\mathrm{ZnO}$ [42-45] can be prepared with good dispersion. Addition of magnesium citrate during or after the precipitation was shown to be beneficial in some cases such as for $\mathrm{Au} / \mathrm{TiO}_{2}$ [46]. The effect of digesting time, calcination temperature and relative ratio of the precursors were studied concerning $\mathrm{CO}$ oxidation in the presence of $\mathrm{O}_{2}$ or $\mathrm{H}_{2}$ (PROX), but no general trends have been depicted.

\subsection{Deposition-Precipitation}

This technique consists of the precipitation of a metal hydroxide or carbonate on the particles of a powder support via the reaction of a base with the precursor of the metal, and was the first efficient method reported to produce highly active gold supported nanoparticles [47]. Rapid nucleation and growth in the solution leads to large crystallites unable to enter into the support pores, leading to a heterogeneous distribution of the metal. To produce good precipitation distributions, an effective mixing and a very slow addition of the base solution must be accomplished. Urea was found to be the best base and is now widely used in many co-precipitation preparations [28]. It is usually added at room temperature and, by rising the temperature to $90{ }^{\circ} \mathrm{C}$, it slowly hydrolyses generating ammonium hydroxide homogeneously through the solution. The rate of precipitation is generally higher than that of hydrolysis and, in this way the $\mathrm{pH}$ of the solution remains practically constant. After the deposition-precipitation step, the product is filtered, washed, dried and calcined as in the coprecipitation procedure. The optimum $\mathrm{pH}$ range for precipitation that also assures an efficient metal utilization $(>90 \%)$ is primarily dictated by the isoelectric point (IEP) of the supporting material. This leads to the main constraint of this method, that is, the inapplicability of the so called acidic oxide $($ IEP $<5)$ such as $\mathrm{SiO}_{2}($ IEP = 2). This method offers the advantage of locating all the active metal onto the support surface, so that no precious metal is wasted in the bulk of the support as in coprecipitation. It is also capable of producing very narrow particle size distributions. However the result is very sensitive to the nature of the support. For example although this method is well established for the preparation of $\mathrm{Au}$ on non-acidic oxides, the use of this method applied to active carbon failed in producing highly dispersed Au nanoparticles (Figure 2).

A reduction step is normally needed after DP deposition. Generally this step is carried out by calcination at $T>500 \mathrm{~K}$ and usually enlargement of $\mathrm{Au}$ nanoparticles is observed by increasing calcination temperature. Quite recently chemical reductions have been proposed with the advantage of obtaining smaller nanoparticles [48]. It should be noted, however, that post-treatment at high temperature 
is expected to increase the support-metal interaction (SMSI) that can play a significant role in catalytic uses $[49,50]$.

Figure 2. TEM image of $\mathrm{Au} / \mathrm{AC}$ prepared by DP method.

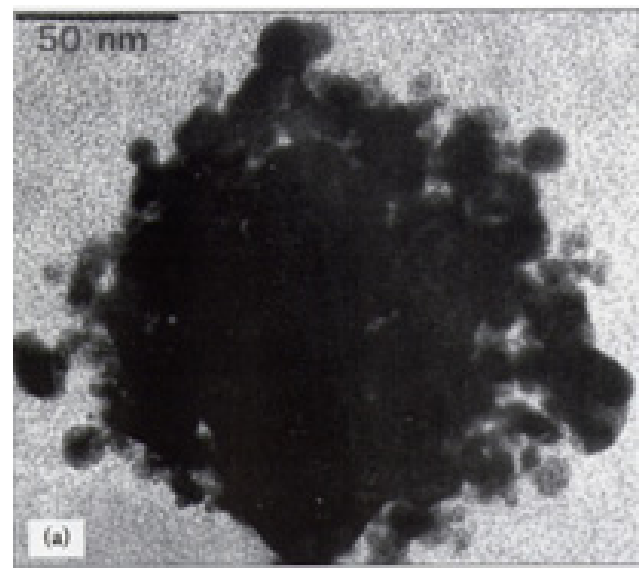

\subsection{Deposition}

These methods could be referred as particular cases of impregnation and can be subdivided as:

a. Metal vapor deposition;

b. Solid grinding;

c. Metallic sol immobilization.

\subsubsection{Metal Vapor Deposition}

Dimethyl-Au(III)-acetyl acetonate can be vaporized in a vacuum system by heating and deposited on support [51]. The method is highly efficient and does not suffer the limitation of DP preparation, i.e., it is applicable to any kind of support. Ligand exchange between $\mathrm{Me}_{2} \mathrm{Au}(\mathrm{acac})$ and the surface hydroxyl groups and adsorbed $\mathrm{H}_{2} \mathrm{O}$ molecules $\left(\mathrm{Al}_{2} \mathrm{O}_{3}\right)$ [51] and hydrogen bonding between oxygen atoms of $\mathrm{Me}_{2} \mathrm{Au}(\mathrm{acac})$ and hydroxyl groups on the support surface $\left(\mathrm{SiO}_{2}\right)$ [52,53] assured the immobilization of the gold precursor on the support surface. After deposition, the samples were calcined at $573 \mathrm{~K}$ to burn out the organic ligands in the gold precursor. The activity observed for prepared catalysts generally increased with their gold dispersion characterized by transmission electron microscopy. Finely dispersed $\mathrm{Au} / \mathrm{Al}_{2} \mathrm{O}_{3}$ (with $\mathrm{d}(\mathrm{Au})<5 \mathrm{~nm}$ ) catalysts may be easily prepared by the CVD method [54]. $\mathrm{Au} / \mathrm{Al}_{2} \mathrm{O}_{3}$ samples prepared by the traditional DP method contained many large gold crystallites $(\mathrm{d}(\mathrm{Au})>7 \mathrm{~nm})$.

More complex, is the improved impregnation method reported by S.H. Wu et al. [55], namely solvated metal atom impregnation (SMAI). This method involves the preparation of an air-sensitive and thermally-unstable bis(toluene) $\mathrm{Au}(0)$ complex solution at $-196^{\circ}$ under dynamic vacuum. The mean diameter of $\mathrm{Au}$ particles prepared by SMAI, results in generally smaller particles than those prepared by conventional impregnation. 
To overcome the limitation of using expensive organometallic precursors, two systems were set up, namely magnetron sputtering and solvated metal atoms dispersion SMAD, which use metallic gold as the starting material.

In the first system a high purity gold attached to a magnetron source was sputtered at an applied power of $14 \mathrm{~W}$ in an argon plasma. The sputtered species were deposited onto the support material as it was tumbled in a rotating stainless steel cup [56]. The magnetron sputtering process entails depositing an atomic flux of gold atoms onto the support surface where the atoms nucleate and grow to form catalyst clusters; nanoparticles form because of low interfacial binding energy between the gold and the support and an insufficient concentration of deposited material to create a thin-film or coating on the substrate. The sputtering process is a line-of-sight technique so only surfaces directly exposed to the metal flux will capture atoms. Consequently catalysts are grown in "egg-shell" like configurations on the outside of a support material and not within a support material or in micropores. Gold loading and particle size are a function of deposition time, material volume, and exposed surface area [57]. An interesting example is the deposition of gold on active carbon which produced a highly active catalyst for liquid phase oxidation where also atomic gold was detected [58]. Nucleation sites likely appears to be functional groups and/or defect sites as represented in Figure 3, showing the Au nanoparticles distribution obtained using active carbon (high number of functionalities and high surface area) and graphite (low number of functionalities and low surface area).

Figure 3. Au by magnetron sputtering on (a) AC and (b) graphite.

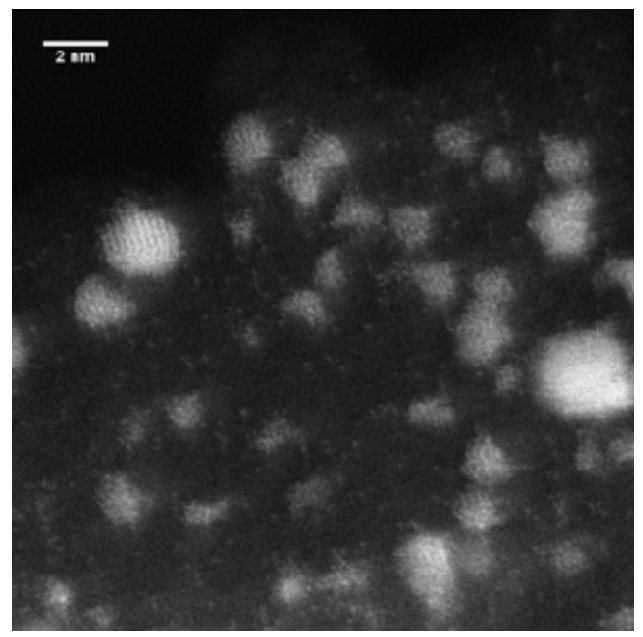

(a)

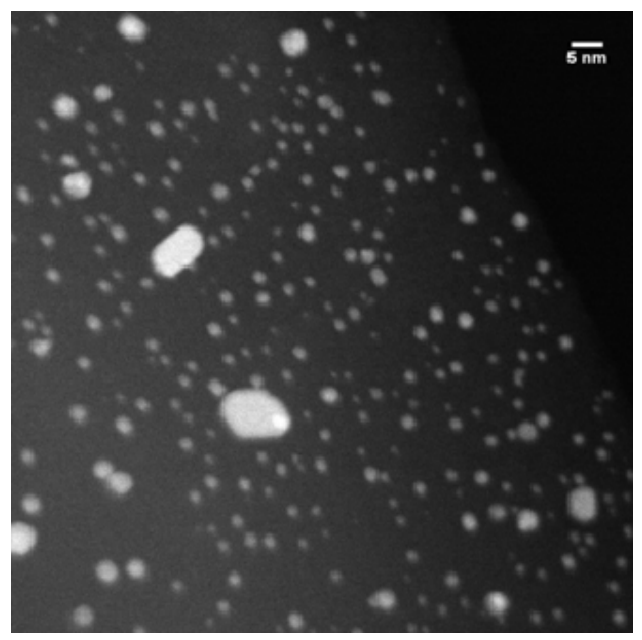

(b)

In the SMAD process, evaporation at reduced pressure of relatively volatile metals by means of resistive heating or electron beam and subsequent co-condensation at low temperatures of these metals, with the vapor of organic solvent on the walls of a reactor cooled with liquid nitrogen. In the vapor phase, in excess of organic vapors, metal atoms are present which are then trapped in the frozen matrix of the solvent. When this frozen metal/organic mixture is allowed to warm, nucleation and growth take place and a colloidal dispersion of the metal was then obtained after melting. SMAD can be used to prepare supported Au catalyst simply by mixing SMAD with solid support and in such a way Au particles of 2 to $15 \mathrm{~nm}$ are deposited on oxide and polymers [59-63]. As in the case of Magnetron sputtered catalyst, AuNPs can be considered as "naked" NPs because no strong coordinating ligands 
are present. The main drawback in employing SMAD for making supported Au catalyst, is the poor reproducibility of the method due to the scarce control in the evaporation of bulk metal.

\subsubsection{Solid Grinding}

Dimethyl-Au(III)-acetyl acetonate was used as solid material thus avoiding any solvent in a procedure called solid grinding (SI) that was fruitfully applied for preparing gold on porous coordinated polymers [64] and then extended to other supports such as active carbons [26]. The gold precursor is ground together with the support using different apparatus, such as mortar or ball milling, and then calcined in air at $300{ }^{\circ} \mathrm{C}$. Similar interactions between $\mathrm{Me}_{2} \mathrm{Au}(\mathrm{acac})$ and the support surface as in the case of vapor deposited can be supposed. The advantage of this technique is the easy applicability to each kind of support.

\subsubsection{Metallic Sol Immobilisation}

The immobilisation of pre-formed metallic sols is also widely applied. The advantage of using this technique principally lies in its applicability regardless of the type of support employed and the possible control on particle size/distribution, obtaining normally highly dispersed metal catalyst $[27,65]$. The method is based on the preparation of Au nanoparticles and their subsequent immobilization on a support. Therefore generally no subsequent catalyst reduction is needed. Thus modifications on morphology and properties of the material which can occur during calcination are avoided. For catalytic applications particle size has to be ranged from 2 to $25 \mathrm{~nm}$ and sols have to show good stability [66-69]. Common procedures include: reduction of metal salts, photochemical or thermal decomposition, and reduction of organometallic complexes [70]. For improving their resistance against coagulation, aqueous colloidal solution of metal particles have been stabilized by three methods: (a) surface potential and/or charge density are increased by the adsorption of surface active long-chain ions (i.e., surfactants); (b) van der Walls forces are reduced by adsorption of relatively rigid hydrophilic macromolecules (i.e., dextrin, starch); (c) besides these stabilizing effects depending on Coulomb or van der Waals forces, a third type of stabilization, "steric stabilization", has been considered [71]. A crucial point in this technique is represented by the immobilization step (Table 1 and Figure 4).

Table 1. Effect of the support on AuPVA particle size during the immobilizing step.

\begin{tabular}{ccc}
\hline Support & TEM (nm) & Reference \\
\hline NiO commercial & 3.8 & {$[72]$} \\
Nano NiO & 3.6 & {$[72]$} \\
$\mathrm{SiO} 2$ & 4.0 & {$[72]$} \\
$\mathrm{MgO}$ & 3.8 & {$[72]$} \\
$\mathrm{TiO}_{2}$ & 4.0 & {$[48]$} \\
$\mathrm{H}-$ mordenite & 3.8 & {$[73]$} \\
$\mathrm{AC} \mathrm{X} 40 \mathrm{~S}$ & 3.0 & {$[74]$} \\
$\mathrm{AC}$ Norit & 3.6 & {$[75]$} \\
CNTs & 4.6 & {$[76]$} \\
\hline
\end{tabular}


Figure 4. Influence of the support functionalities on immobilization of $\mathrm{Au}(\mathrm{PVA})$ sol. (a) carbon nanotubes (CNTs); (b) functionalized CNTs.

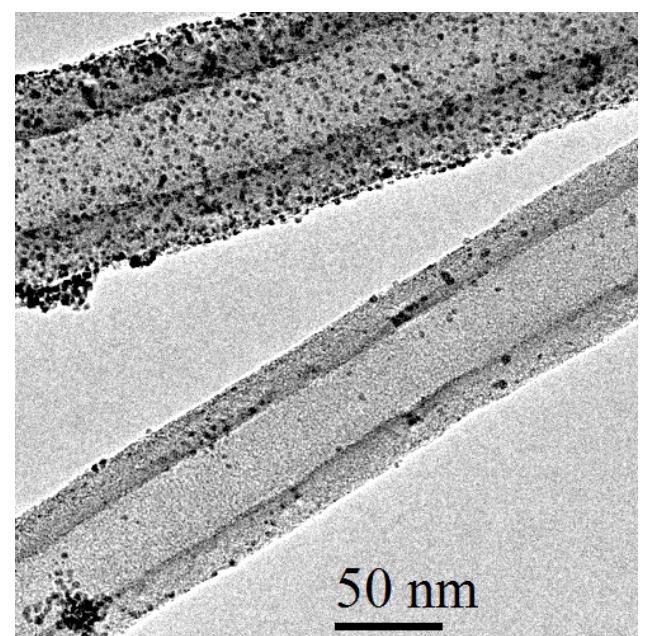

(a)

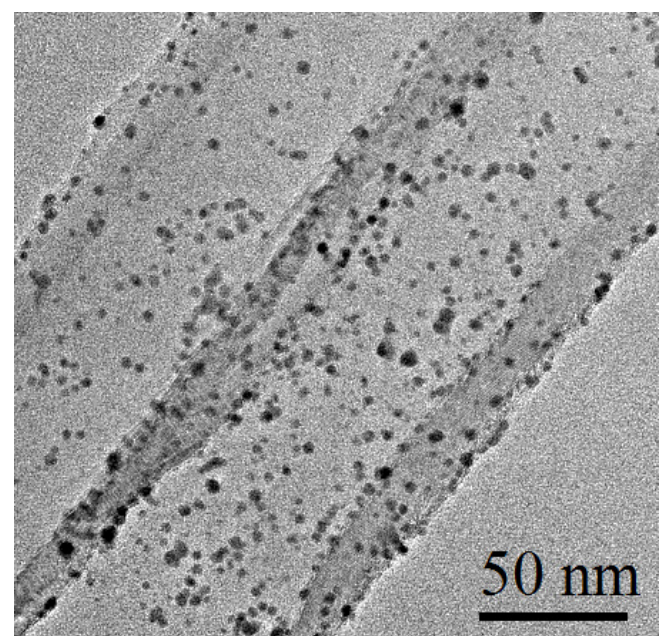

(b)

Normally this step is simply performed by dipping the support in the sol and metal particles resulted adsorbed from the solution. The kinetic of adsorption depends on sol stabilizer and on the IEP and surface area of the support [77]. Adsorption can be therefore modulated by tuning the $\mathrm{pH}$ of the sol.

As shown in Table 1 and Figure 4, the influence of the support nature in obtaining good metal dispersion can be important. As a general trend, it has been shown that metal dispersion increases by increasing functionalities (compare for example $\mathrm{Au}(\mathrm{PVA})$ immobilized on carbon nanotubes in Figure 4(a) and on functionalized carbon nanotubes in Figure 4(b)).

Moreover, the nature of the protective agent is an additional factor influencing the metal dispersion. Figure 5 reports the different Au dispersion on activated carbon using different protective agent.

Figure 5. Influence on the sol in the immobilization step on $\mathrm{AC}$ (a) $\mathrm{Au}_{\mathrm{PVA}}$; (b) $\mathrm{Au}_{\mathrm{THPC}}$ and (c) $\mathrm{Au}_{\text {citrate. }}$.

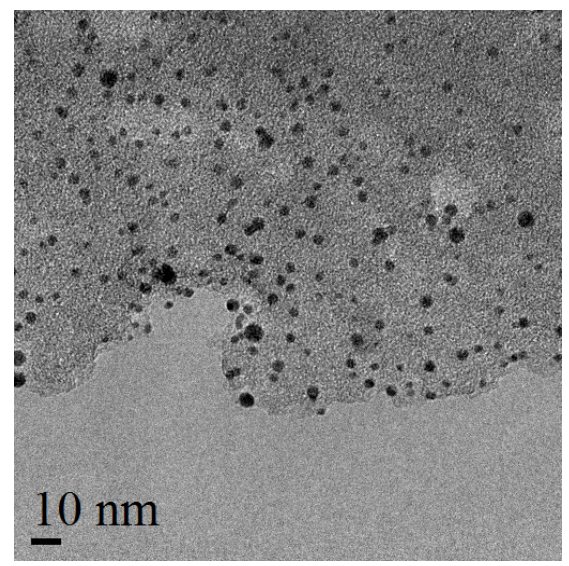

(a)

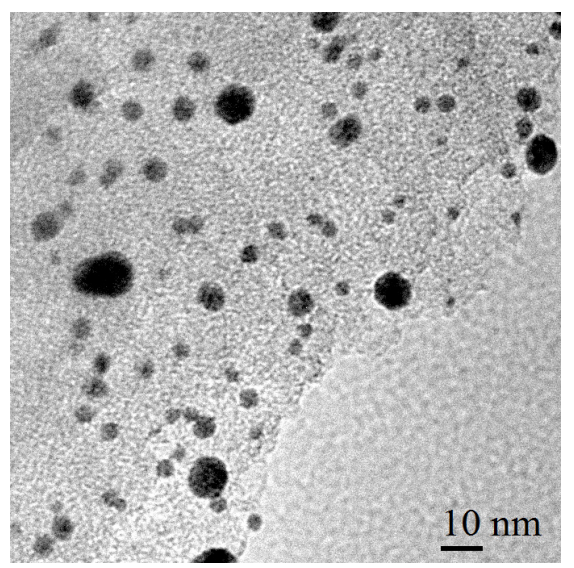

(b)

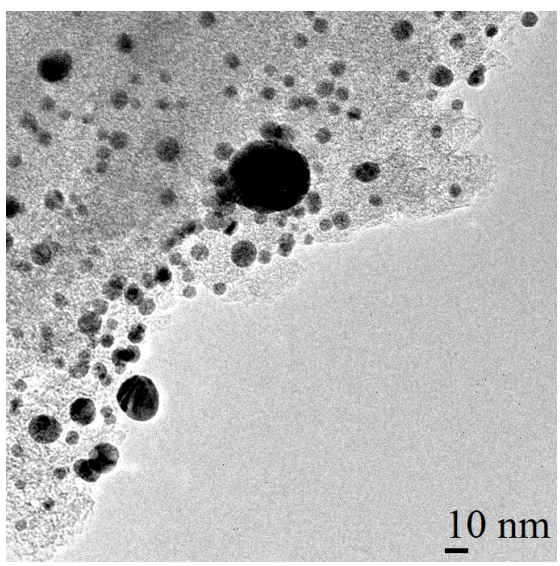

(c)

The stabilizer should be carefully checked depending on the nature of support employed. It has been reported that improving the surface functionalization of the supporting material, a decreasing of aggregation is obtained and higher metallic dispersion observed [78]. The presence of the stabilizer 
should also affect the activity (Figure 6) and can have a positive effect on the durability of the catalyst (Figure 7).

Figure 6. Catalytic activity of $\mathrm{Au} / \mathrm{AC}$ by varying the $\mathrm{Au} /$ protective agent (PVA) weight ratio. Glycerol $0.3 \mathrm{M}, \mathrm{NaOH} 4 \mathrm{eq}, \mathrm{Au} / \mathrm{glycerol}=1 / 1000 \mathrm{~mol} / \mathrm{mol}, p \mathrm{O}_{2}=300 \mathrm{kPa}$, $T=323 \mathrm{~K}$.

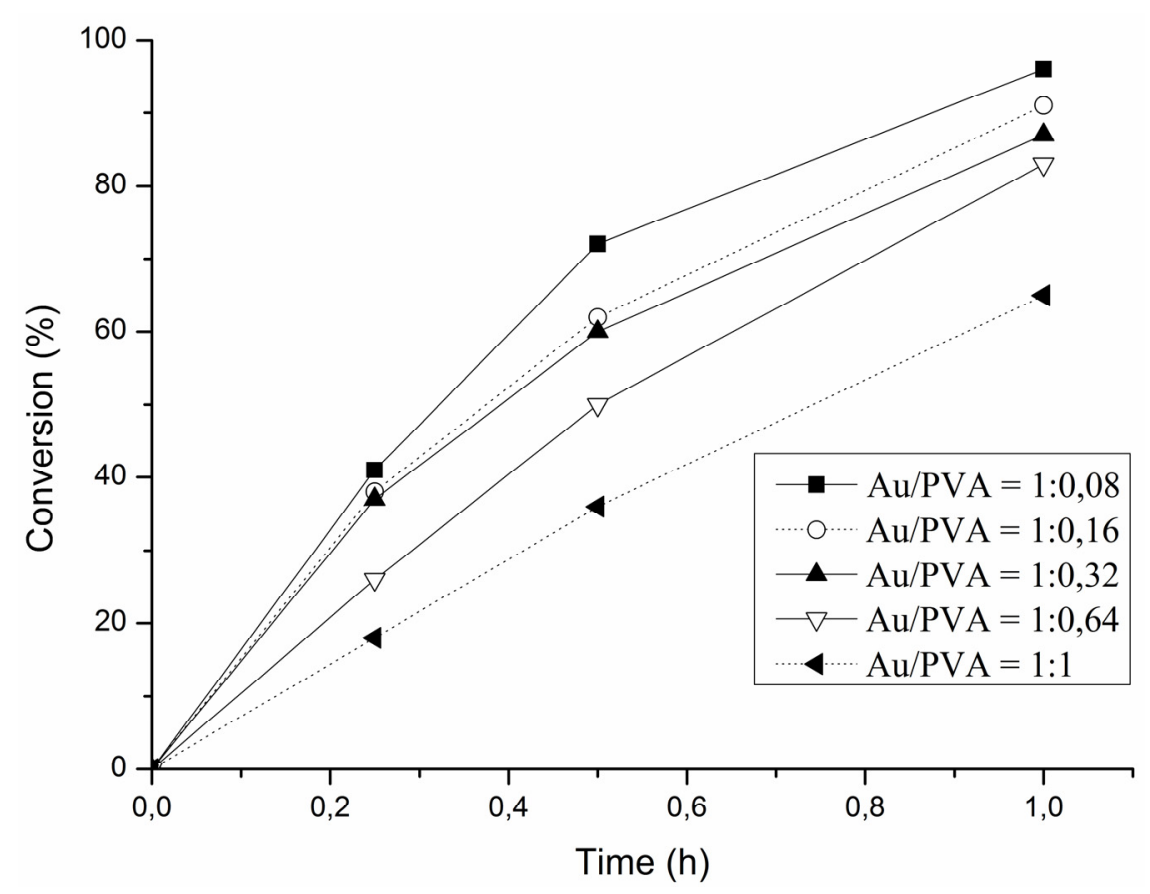

Figure 7. Stability of $\mathrm{Au} / \mathrm{AC}$ by varying the $\mathrm{Au} /$ protective agent (PVA) weight ratio. Glycerol $0.3 \mathrm{M}, \mathrm{NaOH} 4 \mathrm{eq}, \mathrm{Au} / \mathrm{glycerol}=1 / 1000 \mathrm{~mol} / \mathrm{mol}, p \mathrm{O}_{2}=300 \mathrm{kPa}, T=323 \mathrm{~K}$.

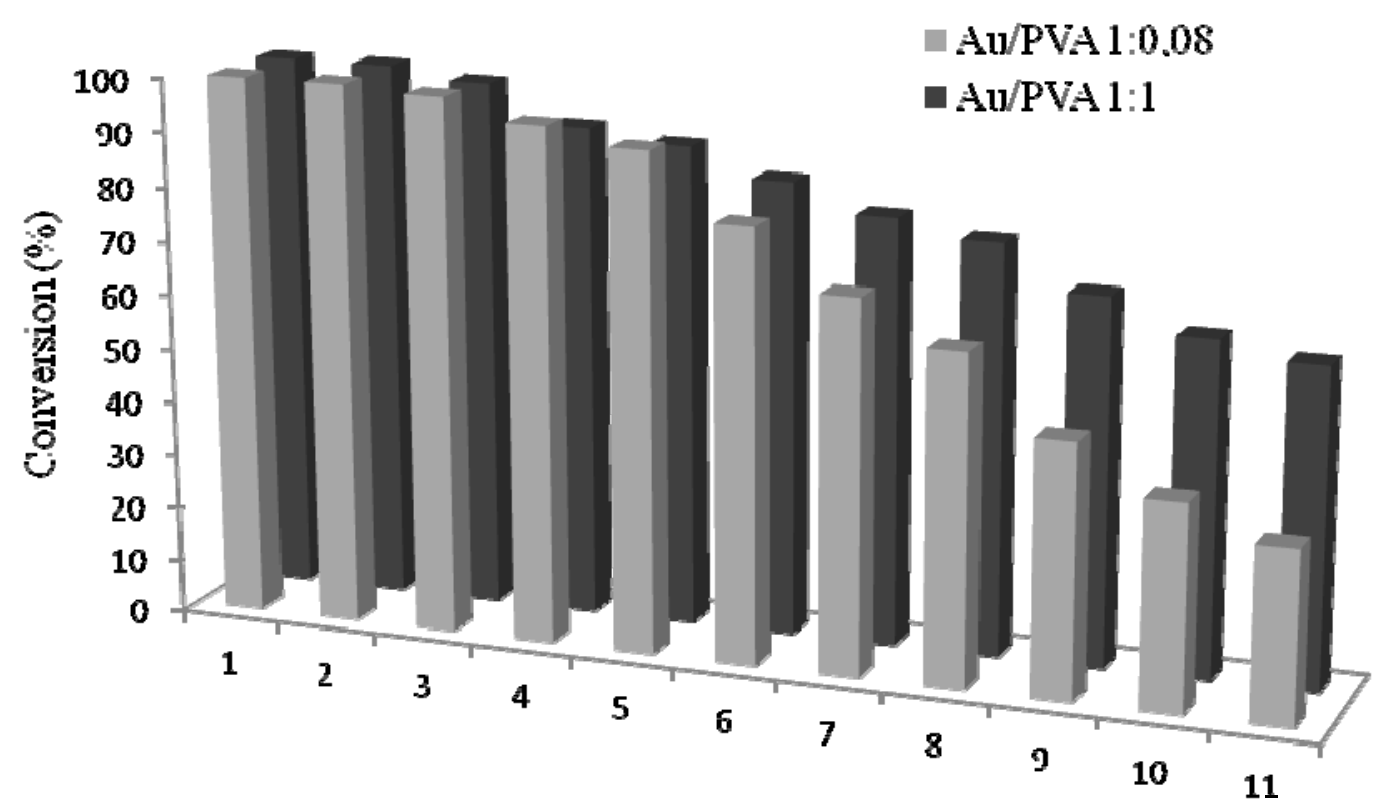

However it has been shown that the protective agent can be removed by thermal decomposition or under milder conditions by solvent washing [79]. This latter method has the advantage of limiting the coarsening of metallic nanoparticles that normally occurs during thermal treatment. 


\section{Conclusions}

Gold is the most inert of all the metallic elements. However, at a nanoscale level, it presents peculiar properties as a catalytic material. Academic and industrial interests are recorded in the vast amount of literature and patents on this subject. However, much has not yet been understood and apparently similar preparations can lead to catalytic material showing activities of a different magnitude. A lot of parameters are indeed important in gold catalyst preparation (precursor, methodology, support, etc.) and the intricate evaluation of the catalytic activity/selectivity could be restrictive. The industrial use of gold catalysts will be boosted only when stable, long-life catalysts become available. Single cases have been solved but a more general approach is still needed.

\section{References}

1. Haruta, M.; Kobayashi, T.; Sano, H.; Yamada, N. Novel gold catalysts for the oxidation of carbon monoxide at a temperature far below $0{ }^{\circ} \mathrm{C}$. Chem. Lett. 1987, 405, 405-408.

2. Hutchings, G.J. Vapor phase hydrochlorination of acetylene: Correlation of catalytic activity of supported metal chloride catalysts. J. Catal. 1985, 96, 292-295.

3. Bond, G.C.; Thompson, D.T. Catalysis by gold. Catal. Rev. Sci. Eng. 1999, 41, 319-388.

4. Bond, G.C.; Louis, C.; Thompson, D.T. Catalysis by Gold; Hutchings, G.J., Ed.; Catalytic Science Series 6; ICP Covent Garden: London, UK, 2006.

5. Haruta, M. Size and support dependency in the catalysis by gold. Catal. Today 1997, 36, 153-166.

6. Haruta, M. Gold as a novel catalyst in the 21st century: Preparation, working mechanism and applications. Gold Bull. 2004, 37, 27-36.

7. Hutchings, G.J. Catalysis by gold. Catal. Today 2005, 100, 55-61.

8. Hashmi, A.S.K. The catalysis gold rush. Angew. Chem. Int. Ed. 2005, 44, 6990-6993.

9. Della Pina, C.; Falletta, E.; Prati, L.; Rossi, M. Selective oxidation using gold. Chem. Soc. Rev. 2008, 37, 2077-2095.

10. Corma, A.; Garcia, H. Supported gold nanoparticles as catalysts for organic reactions. Chem. Soc. Rev. 2008, 37, 2096-2126.

11. Su, Y.S.; Lee, M.Y.; Lin, S.D. XPS and DRS of $\mathrm{Au} / \mathrm{TiO}_{2}$ catalysts: Effect of pretreatment. Catal. Lett. 1999, 57, 49-53.

12. Pestryakov, A.N.; Lunin, V.V. Physicochemical study of active sites of metal catalysts for alcohol partial oxidation. J. Mol. Catal. A Chem. 2000, 158, 325-329.

13. Pestryakov, A.N.; Lunin, V.V.; Kharlanov, A.N.; Kochubey, D.I.; Bogdanchikova, N.; Stakheev, A.Y. Influence of modifying additives on electronic state of supported gold. $J$. Mol. Struct. 2002, 642, 129-136.

14. Margitfalvi, J.L.; Fasi, A.; Hegedus, M.; Lonyi, F.; Gobolos, S.; Bogdanchikova, N. Au/MgO catalysts modified with ascorbic acid for low temperature $\mathrm{CO}$ oxidation. Catal. Today 2002, 72, 157-169.

15. Lee, S.J.; Gavriilidis, A. Supported Au catalysts for low-temperature CO oxidation prepared by impregnation. J. Catal. 2002, 206, 305-313. 
16. Xu, Q.; Kharas, K.C.C.; Datye, A.K. The preparation of highly dispersed $\mathrm{Au} / \mathrm{Al}_{2} \mathrm{O}_{3}$ by aqueous impregnation. Catal. Lett. 2003, 85, 229-235.

17. Baatz, C.; Decker, N.; Pruße, U. New innovative gold catalysts prepared by an improved incipient wetness method. J. Catal. 2008, 258, 165-169.

18. Ivanova, S.; Pitchon, C. A new preparation method for the formation of gold nanoparticles on an oxide support. Appl. Catal. A 2004, 267, 191-201.

19. Ivanova, S.; Pitchon, V.; Zimmermann, Y.; Petit, C. Preparation of alumina supported gold catalysts: Influence of washing procedures, mechanism of particles size growth. Appl. Catal. A 2006, 298, 57-64.

20. Ivanova, A.; Pitchon, V.; Petit, C.; Heeerschbach, H.; van Dorsselaer, A.; Leize, E. Preparation of alumina supported gold catalysts: Gold complexes genesis, identification and speciation by mass spectrometry. Appl. Catal. A 2006, 298, 203-210.

21. Liu, H.C.; Kozlov, A.I.; Kozlova, A.P.; Shido, T.; Iwasawa, Y. Active oxygen species and reaction mechanism for low-temperature $\mathrm{CO}$ oxidation on an $\mathrm{Fe}_{2} \mathrm{O}_{3}$-supported $\mathrm{Au}$ catalyst prepared from $\mathrm{Au}\left(\mathrm{PPh}_{3}\right)\left(\mathrm{NO}_{3}\right)$ and as-precipitated iron hydroxide. Phys. Chem. Chem. Phys. 1999, 1, 2851-2860.

22. Liu, H.; Kozlov, A.I.; Kozlova, A.P.; Shido, T.; Asakura, K.; Iwasawa, Y. Active oxygen species and mechanism for low-temperature $\mathrm{CO}$ oxidation reaction on a $\mathrm{TiO}_{2}$-supported au catalyst prepared from $\mathrm{Au}\left(\mathrm{PPh}_{3}\right)\left(\mathrm{NO}_{3}\right)$ and as-precipitated titanium hydroxide. J. Catal. 1999, 185, 252-264.

23. Kozlov, A.I.; Kozlova, A.P.; Asakura, K.; Matsui, Y.; Kogure, T.; Shido, T.; Iwasawa, Y. Supported gold catalysts prepared from a gold phosphine precursor and as-precipitated metal-hydroxide precursors: Effect of preparation conditions on the catalytic performance. J. Catal. 2000, 196, 56-65.

24. Olea, M.; Kunitake, M.; Shido, T.; Iwasawa, Y. TAP study on CO oxidation on a highly active $\mathrm{Au} / \mathrm{Ti}(\mathrm{OH})_{4}\left({ }^{*}\right)$ catalyst. Phys. Chem. Chem. Phys. 2001, 3, 627-631.

25. Parks, G.A. The isoelectric points of solid oxides, solid hydroxides, and aqueous hydroxo complex systems. Chem. Rev. 1965, 65, 177-198.

26. Okatsu, H.; Kinoshita, N.; Akita, T.; Ishida, T.; Haruta, M. Deposition of gold nanoparticles on carbons for aerobic glucose oxidation. Appl. Catal. A 2009, 369, 8-14.

27. Prati, L.; Martra, G. New gold catalysts for liquid phase oxidation. Gold Bull. 1999, 32, 96-101.

28. Zanella, R.; Giorgio, S.; Henry, C.R.; Luis, C. Alternative methods for the preparation of gold nanoparticles supported on $\mathrm{TiO}_{2}$. J. Phys. Chem B 2002, 106, 7634-7642.

29. Kahlich, M.J.; Gasteiger, H.A.; Behm, R.J. Kinetics of the selective low-temperature oxidation of $\mathrm{CO}$ in H-2-rich gas over Au/Alpha- $\mathrm{Fe}_{2} \mathrm{O}_{3}$. J. Catal. 1999, 182, 430-440.

30. Schubert, M.M.; Kahlich, M.J.; Gasteiger, H.A.; Behm, R.J. Correlation between CO surface coverage and selectivity/kinetics for the preferential $\mathrm{CO}$ oxidation over Pt/Gamma- $\mathrm{Al}_{2} \mathrm{O}_{3}$ and $\mathrm{Au} /$ Alpha- $\mathrm{Fe}_{2} \mathrm{O}_{3}$ : An in-situ DRIFTS study. J. Power Sources 1999, 84, 175-182.

31. Schubert, M.M.; Venugopal, A.; Kahlich, M.J.; Plzak, V.; Behm, R.J. Influence of $\mathrm{H}_{2} \mathrm{O}$ and $\mathrm{CO}_{2}$ on the selective $\mathrm{CO}$ oxidation in $\mathrm{H}-2$-rich gases over $\mathrm{Au} / \mathrm{Alpha}-\mathrm{Fe}_{2} \mathrm{O}_{3}$. J. Catal. 2004, 222, 32-40.

32. Schubert, M.M.; Haring, T.P.; Brath, G.; Gasteiger, H.A.; Behm, R.J. New DRIFTS cell design for the simultaneous acquisition of Ir spectra and kinetic data using on-line product analysis. Appl. Spectrosc. 2001, 55, 1537-1543. 
33. Finch, R.M.; Hodge, N.A.; Hutchings, G.J.; Meagher, A.; Pankhurst, Q.A.; Siddiqui, M.R.H.; Wagner, F.E.; Whyman, R. Identification of active phases in Au-Fe catalysts for low-temperature CO oxidation. Phys. Chem. Chem. Phys. 1999, 1, 485-489.

34. Hodge, N.A.; Kiely, C.J.; Whyman, R.; Siddiqui, M.R.H.; Hutchings, G.J.; Pankhurst, Q.A.; Wagner, F.E.; Rajaram, R.R.; Golunski, S.E. Microstructural comparison of calcined and uncalcined gold/iron-oxide catalysts for low-temperature CO oxidation. Catal. Today 2002, 72, $133-144$.

35. Wagner, F.E.; Galvagno, S.; Milone, C.; Visco, A.M.; Stievano, L.; Calogero, S. Mössbauer characterisation of gold/iron oxide catalysts. J. Chem. Soc. Faraday Trans. 1997, 93, 3403-3409.

36. Gupta, N.M.; Tripathi, A.K. Microcalorimetry, adsorption, and reaction studies of CO, O-2, and $\mathrm{CO}+\mathrm{O}-2$ over $\mathrm{Fe}_{2} \mathrm{O}_{3}, \mathrm{Au} / \mathrm{Fe}_{2} \mathrm{O}_{3}$, and polycrystalline gold catalysts as a function of reduction treatment. J. Catal. 1999, 187, 343-347.

37. Tripathi, A.K.; Kamble, V.S.; Gupta, N.M. Microcalorimetry, adsorption, and reaction studies of $\mathrm{CO}, \mathrm{O}-2$, and $\mathrm{CO}+\mathrm{O}-2$ over $\mathrm{Au} / \mathrm{Fe}_{2} \mathrm{O}_{3}, \mathrm{Fe}_{2} \mathrm{O}_{3}$, and polycrystalline gold catalysts. J. Catal. 1999, $187,332-342$.

38. Gupta, N.M.; Tripathi, A.K. The role of nanosized gold particles in adsorption and oxidation of carbon monoxide over $\mathrm{Au} / \mathrm{Fe}_{2} \mathrm{O}_{3}$ catalyst. Gold Bull. 2001, 34, 120-128.

39. Horvath, D.; Toth, L.; Guczi, L. Gold nanoparticles: Effect of treatment on structure and catalytic activity of $\mathrm{Au} / \mathrm{Fe}_{2} \mathrm{O}_{3}$ catalyst prepared by Co-precipitation. Catal. Lett. 2000, 67, 117-128.

40. Minico, S.; Scire, S.; Crisafulli, C.; Galvagno, S. Influence of catalyst pretreatments on volatile organic compounds oxidation over gold/iron oxide. Appl. Catal. B 2001, 34, 277-285.

41. Lee, S.J.; Gavriilidis, A.; Pankhurst, Q.A.; Kyek, A.; Wagner, F.E.; Wong, P.C.L.; Yeung, K.L. Effect of drying conditions of Au-Mn Co-precipitates for low-temperature $\mathrm{CO}$ oxidation. J. Catal. 2001, 200, 298-308.

42. Bailie, J.E.; Abdullah, H.A.; Anderson, J.A.; Rochester, C.H.; Richardson, N.V.; Hodge, N.; Zhang, J.G.; Burrows, A.; Kiely, C.J.; Hutchings, G.J. Hydrogenation of but-2-enal over supported Au/ZnO catalysts. Phys. Chem. Chem. Phys. 2001, 3, 4113-4121.

43. Wang, G.Y.; Zhang, W.X.; Lian, H.L.; Liu, Q.S.; Jiang, D.Z.; Wu, T.H. Effect of Au loading, $\mathrm{H}_{2} \mathrm{O}$ and $\mathrm{CO}$ concentration on the stability of $\mathrm{Au} / \mathrm{ZnO}$ catalysts for room-temperature $\mathrm{CO}$ oxidation. React. Kinet. Catal. Lett. 2002, 75, 343-351.

44. Wang, G.Y.; Zhang, W.X.; Lian, H.L.; Jiang, D.Z.; Wu, T.H. Effect of calcination temperatures and precipitant on the catalytic performance of $\mathrm{Au} / \mathrm{ZnO}$ catalysts for $\mathrm{CO}$ oxidation at ambient temperature and in humid circumstances. Appl. Catal. A 2003, 239, 1-10.

45. Sakurai, H.; Haruta, M. Carbon dioxide and carbon monoxide hydrogenation over gold supported on titanium, iron, and zinc oxides. Appl. Catal. A 1995, 127, 93-105.

46. Tsubota, S.; Haruta, M.; Kobayashi, T.; Ueda, A.; Nakahara, Y. Preparation of highly dispersed gold on titanium and magnesium oxide. Stud. Surf. Sci. Catal. 1991, 63, 695-704.

47. Okumura, M.; Tsubota, S.; Iwamoto, M.; Haruta, M. Chemical vapor deposition of gold nanoparticles on MCM-41 and their catalytic activities for the low-temperature oxidation of CO and of $\mathrm{H}_{2}$. Chem. Lett. 1998, 27, 315-316.

48. Dimitratos, N.; Villa, A.; Bianchi, C.L.; Prati, L.; Makkee, M. Gold on titania: Effect of preparation method in the liquid phase oxidation. Appl. Catal. A 2006, 311, 185-192. 
49. Vannice, M.A. The influence of MSI (metal-support interactions) on activity and selectivity in the hydrogenation of aldehydes and ketones. Top. Catal. 1997, 4, 241-248.

50. Weerachawanasak, P.; Mekasuwandumrong, O.; Arai, M.; Fujita, A.-I.; Praserthdam, P.; Panpranot, J. Effect of strong metal-support interaction on the catalytic performance of $\mathrm{Pd} / \mathrm{TiO} 2$ in the liquid-phase semihydrogenation of phenylacetylene. J. Catal. 2009, 262, 199-205.

51. Guzman, J.; Gates, B.C. Reactions of $\mathrm{Au}\left(\mathrm{CH}_{3}\right)_{2}$ (acac) on $\gamma-\mathrm{Al}_{2} \mathrm{O}_{3}$ : Characterization of the surface organic, organometallic, metal oxide, and metallic species. Langmuir 2003, 19, 3897-3903.

52. Okumura, M.; Tsubota, S.; Haruta, M. Preparation of supported gold catalysts by gas-phase grafting of gold acethylacetonate for low-temperature oxidation of $\mathrm{CO}$ and of $\mathrm{H}_{2}$. J. Mol. Catal. A 2003, 199, 73-84.

53. Chen, Y.J.; Yeh, C.T. Deposition of highly dispersed gold on alumina support. J. Catal. 2001, 200, 59-68.

54. Schimpf, S.; Lucas, M.; Mohr, C.; Rodemerck, U.; Bruckner, A.; Radnik, J.; Hofmeister, H.; Claus, P. Supported gold nanoparticles: In-depth catalyst characterization and application in hydrogenation and oxidation reactions. Catal. Today 2002, 72, 63-78.

55. Wu, S.H.; Li, B.Q.; Huang, W.P.; Zhang, S.M.; Shi, J.; Zheng, X.C. Comparative studies of gold catalysts prepared via solvated metal atom impregnation and conventional impregnation: Characterization and low-temperature CO oxidation. React. Kinet. Catal. Lett. 2003, 78, 49-58.

56. Veith, G.M.; Lupini, A.R.; Pennycook, S.J.; Ownby, G.W.; Dudney, N.J. Nanoparticles of gold on $\gamma-\mathrm{Al}_{2} \mathrm{O}_{3}$ produced by de magnetron sputtering. J. Catal. 2005, 231, 151-158.

57. Veith, G.M.; Lupini, A.R.; Pennycook, S.J.; Dudney, N.J. The use of magnetron sputtering for the production of heterogeneous catalysts. Stud. Surf. Sci. Catal. 2006, 162, 71-78.

58. Veith, G.M.; Lupini, A.R.; Pennycook, S.J.; Villa, A.; Prati, L.; Dudney, N.J. Magnetron sputtering of gold nanoparticles onto $\mathrm{WO}_{3}$ and activated carbon. Catal. Today 2007, 122, 248-253.

59. Lin, S.T.; Franklin, M.T.; Klabunde, K.J. Nonaqueous colloidal gold. Clustering of metal atoms in organic media, 12. Langmuir 1986, 2, 259-260.

60. Cardenas-Trivino, G.; Klabunde, K.J.; Brock Dale, E. Living colloidal palladium in nonaqueous solvents. Formation, stability, and film-forming properties. Clustering of metal atoms in organic media, 14. Langmuir 1987, 3, 986-992.

61. Klabunde, K.J.; Habdas, J.; Cardenas-Trivino, G. Colloidal metal particles dispersed in monomeric and polymeric styrene and methyl methacrylate. Chem. Mater. 1989, 1, 481-483.

62. Olsen, A.W.; Kafafi, Z.H. Gold cluster-laden polydiacetylenes: Novel materials for nonlinear optics. J. Am. Chem. Soc. 1991, 113, 7758-7760.

63. Zuckerman, E.B.; Klabunde, K.J.; Olivier, B.J.; Sorensen, C.M. Nonaqueous perfluorocarbon-derived gold colloids. 1. Clustering of metal atoms in fluorocarbon media. Chem. Mater. 1989, 1, 12-14.

64. Ishida, T.; Nagaoka, M.; Akita, T.; Haruta, M. Deposition of gold clusters on porous cordination polymers by solid grinding and their catalystic activity in aerobic oxidation of alcohols. Chem. Eur. J. 2008, 14, 8456-8460.

65. Duff, D.G.; Baiker, A.; Edwards, P.P. A new hydrosol of gold cluster. J. Chem. Soc. Chem. Commun. 1993, 96-98.

66. Porta, F.; Prati, L. Pre-formed gold particle immobilized on supports: Preparation and catalytic applications. Recent Res. Dev. Vac. Sci. Technol. 2003, 4, 99-110. 
67. Villa, A.; Wang, D.; Su, D.S.; Prati, L. Gold sols as catalyst in the glycerol oxidation: The role of stabilizer. Chem. Catal. Chem. 2009, 1, 510-514.

68. Comotti, M.; Della Pina, C.; Matarrese, R.; Rossi, M.; Siani, A. Oxidation of alcohols and sugars using Au/C catalysts part 2. Sugars. Appl. Catal. A 2005, 291, 204-209.

69. Comotti, M.; Li, W-C.; Spliethoff, B.; Schuth, F. Support effect in high activity gold catalysts for CO oxidation. J. Am. Chem. Soc. 2006, 128, 917-924.

70. Bradley, J.S. Cluster and Colloids: From Theory to Applications; Schmid, G., Ed.; VCH Pub: New York, NY, USA, 1994; Chapter 6.

71. Heller, W.; Pugh, T.L. Steric stabilization of colloidal solutions by adsorption of flexible macromolecules. J. Polym. Sci. 1960, 47, 203-217.

72. Villa, A.; Chan-Thaw, C.E.; Veith, G.M.; More, K.L.; Ferri, D.; Prati, L. Au on nanosized NiO: A cooperative effect between $\mathrm{Au}$ and nanosized $\mathrm{NiO}$ in the base-free alcohol oxidation. Chem. Catal. Chem. 2011, 3, 1612-1618.

73. Villa, A.; Veith, G.M.; Prati, L. Selective oxidation of glycerol under acidic conditions using gold catalysts. Angew. Chem. Int. Ed. 2010, 49, 4499-4502.

74. Villa, A.; Wang, D.; Su, D.; Veith, G.M.; Prati, L. Using supported Au nanoparticles as starting material for preparing uniform $\mathrm{Au} / \mathrm{Pd}$ bimetallic catalysts. Phys. Chem. Chem. Phys. 2010, 12, 2183-2189.

75. Dimitratos, N.; Lopez-Sanchez, J.A.; Morgan, D.; Carley, A.; Prati, L.; Hutchings, G.J. Solvent free liquid phase oxidation of benzyl alcohol using Au supported catalysts prepared using a sol immobilization technique. Catal. Today 2007, 122, 317-324.

76. Prati, L.; Villa, A.; Chan-Thaw, C.E.; Arrigo, R.; Wang, D.; Su, D.S. Gold catalyzed liquid phase oxidation of alcohol: The issue of selectivity. Faraday Discuss. 2011, 152, 353-365.

77. Coluccia, S.; Martra, G.; Porta, F.; Prati, L.; Rossi, M. Metal sols as a useful tool for heterogeneous gold catalyst preparation: Reinvestigation of a liquid phase oxidation. Catal. Today 2000, 61, 165-172.

78. Villa, A.; Wang, D.; Spontoni, P.; Arrigo, R.; Su, D.; Prati, L. Nitrogen functionalized carbon nanostructures supported $\mathrm{Pd}$ and $\mathrm{Au}-\mathrm{Pd} \mathrm{NPs}$ as catalyst for alcohols oxidation. Catal. Today 2010, 157, 89-93.

79. Lopez-Sanchez, J.A.; Dimitratos, N.; Hammond, C.; Brett, G.L.; Kesavan, L.; White, S.; Miedziak, P.; Tiruvalam, R.; Jenkins, R.L.; Carley, A.F.; et al. Facile removal of stabilizer-ligands from supported gold nanoparticles. Nat. Chem. 2011, 3, 551-556.

(C) 2012 by the authors; licensee MDPI, Basel, Switzerland. This article is an open access article distributed under the terms and conditions of the Creative Commons Attribution license (http://creativecommons.org/licenses/by/3.0/). 